\title{
Neurologic Manifestations of Hypoglycemia
}

\author{
William P. Neil and Thomas M. Hemmen \\ University of California, San Diego \\ United States of America (USA)
}

\section{Introduction}

Unlike most other body tissues, the brain requires a continuous supply of glucose. It has very limited endogenous glycogen stores, and does not produce glucose intrinsically. ${ }^{1}$ Although it accounts for $2 \%$ of body weight, the brain utilizes $25 \%$ of the body's glucose due to its high metabolic rate.2, 3 Evidence for the brains sole reliance on glucose came from obtaining a respiratory quotient of one after measuring differences between arterial and venous content of oxygen and carbon dioxide in blood traveling through the brain. ${ }^{4}$

In the past, neurons were thought to directly metabolize glucose, however, more recent studies suggest astrocytes may play an important role in glucose metabolism. ${ }^{5}$ Astrocytic foot processes surround brain capillaries, which deliver glucose to the brain. With this, they form the first cellular barrier for entering glucose..$^{5}$ Astrocytes contain the non-insulin dependent GLUT1 transporter, as well as the insulin dependent GLUT4 transporter, suggesting a possible role for astrocytes in regulating and storing brain glucose in an insulin dependent and independent manner (see figure 1). ${ }^{6-8}$

In addition to glucose, the brain contains a very limited store of glycogen, (between 0.5 and $1.5 \mathrm{~g}$, or about $0.1 \%$ of total brain weight). Unlike peripheral tissue, where glycogen is readily mobilized during hypoglycemia, the brain can only function normally for a limited duration. Glycogen content seems to fall in areas of highest brain metabolic rate, suggesting at least some, albeit limited role as fuel during hypoglycemia. ${ }^{7}$

Although the brain relies primarily on glucose during normal conditions, it can use ketone bodies during starvation. These ketone bodies cannot however meet all of the metabolic demands of the brain. ${ }^{9}$

\section{Pathophysiology}

The brain areas most vulnerable to hypoglycemia are (in order) the subiculum, small and medium sized caudate neurons, area CA1 of the hippocampus, the dentate gyrus and superficial cortical layers, specifically layers 2 and 3.10 Damage induced by hypoglycemia in the rat brain was not limited to a particular type of neuron, but those near the cerebrospinal fluid (CSF) spaces seemed to be more vulnerable. ${ }^{10}$ Similar distribution of injury was shown in autopsy of three human subjects with hypoglycemia. ${ }^{11}$

Excitatory amino acids such as glutamate and aspartate were found in larger than normal quantities in the CSF space of hypoglycemic animals.12, 13 These increases occur as a result of less glucose as a substrate for the tricarboxylic acid (TCA) cycle during hypoglycemia. Lower glucose levels ultimately lead to lower acetate levels. This, in turn causes oxaloacetate 


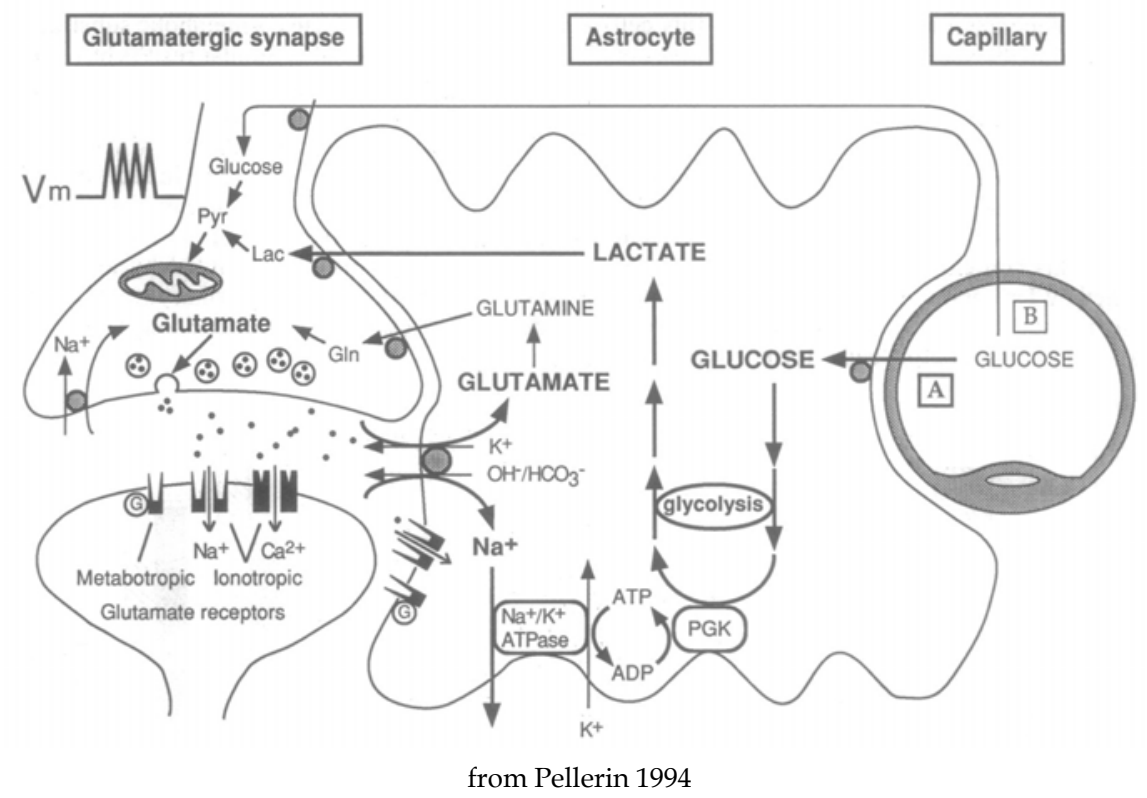

Fig. 1. Schematic of the mechanism for glutamate-induced glycolysis in astrocytes during physiological activation. At glutamatergic synapses, glutamate depolarizes neurons by acting at specific receptor subtypes. The action of glutamate is terminated by an efficient glutamate uptake system located primarily in astrocytes. Glutamate is cotransported with $\mathrm{Na}^{+}$, resulting in an increase in $\left[\mathrm{Na}^{+}\right] \mathrm{i}$, leading to activation of $\mathrm{Na}^{+} / \mathrm{K}^{+}$-ATPase. The pump, fuled by ATP provided by membrane-bound glycolytic enzymes[possibly phosphoglycerate kinase(PGK); see ref. 22], activates glycolysis-i.e., glucose utilization and lactate productionin astrocytes. Lactate, once released, can bi taken up by neurons and serve as an adequate energy substrate. For graphic clarity, only lactate uptake into presynaptic terminals is indicated. However, this process could also occur at the postsynaptic neuron. Based on recent evidence, glutamate receptors are also shown on astrocytes(12). This model, which summarizes in vitro experimental evidence indicating glutamate-induced glycolysis, is taken to reflect cellular and molecular events occurring during activation of a given cortical area[arrow labeled A(activation)]. Direct glucose uptake into neurons under basal conditions is also shown[arrow labeled B(basal conditions)]. Pyr, pyruvate; Lac, lactate; Gln, glutamine; G, guanine nucleotide binding protein.

to form aspartate, and $\alpha$ ketoglutarate to form glutamate (see figure 2). ${ }^{14,15}$ Glutamate and aspartate build up in the tissue, then interstitial space and ultimately CSF space. ${ }^{12}$ These findings suggest the possibility of an excitotoxic agent rather than insufficient glucose substrate as a cause for neuronal dysfunction and death during hypoglycemia. ${ }^{10}$

Glutamate and aspartate cause sustained glutamate receptor activation, particularly at the NMDA receptor. ${ }^{16-19}$ The excess glutamate and aspartate activation leads initially to sodium and water influx which causes cellular edema. ${ }^{20}$ This is followed by calcium (an important neuronal second messenger) influx into the cells, which causes dysfunction of many intracellular processes. ${ }^{21-24}$ NMDA receptor activation leads to the production of reactive 
oxygen species which damage neuronal DNA. ${ }^{25}$ The DNA damage in turn activates poly (ADP-ribose) polymerase-1 (PARP-1). Under normal conditions, PARP-1 acts to repair DNA, but with extensive damage, it can increase apoptosis inducing factor and stimulate cell death (see figure 3).26, 27 Hypoglycemic neuronal death can be halted by severing glutamatergic axons, or by blocking glutamate receptors in animals. ${ }^{17,18}$

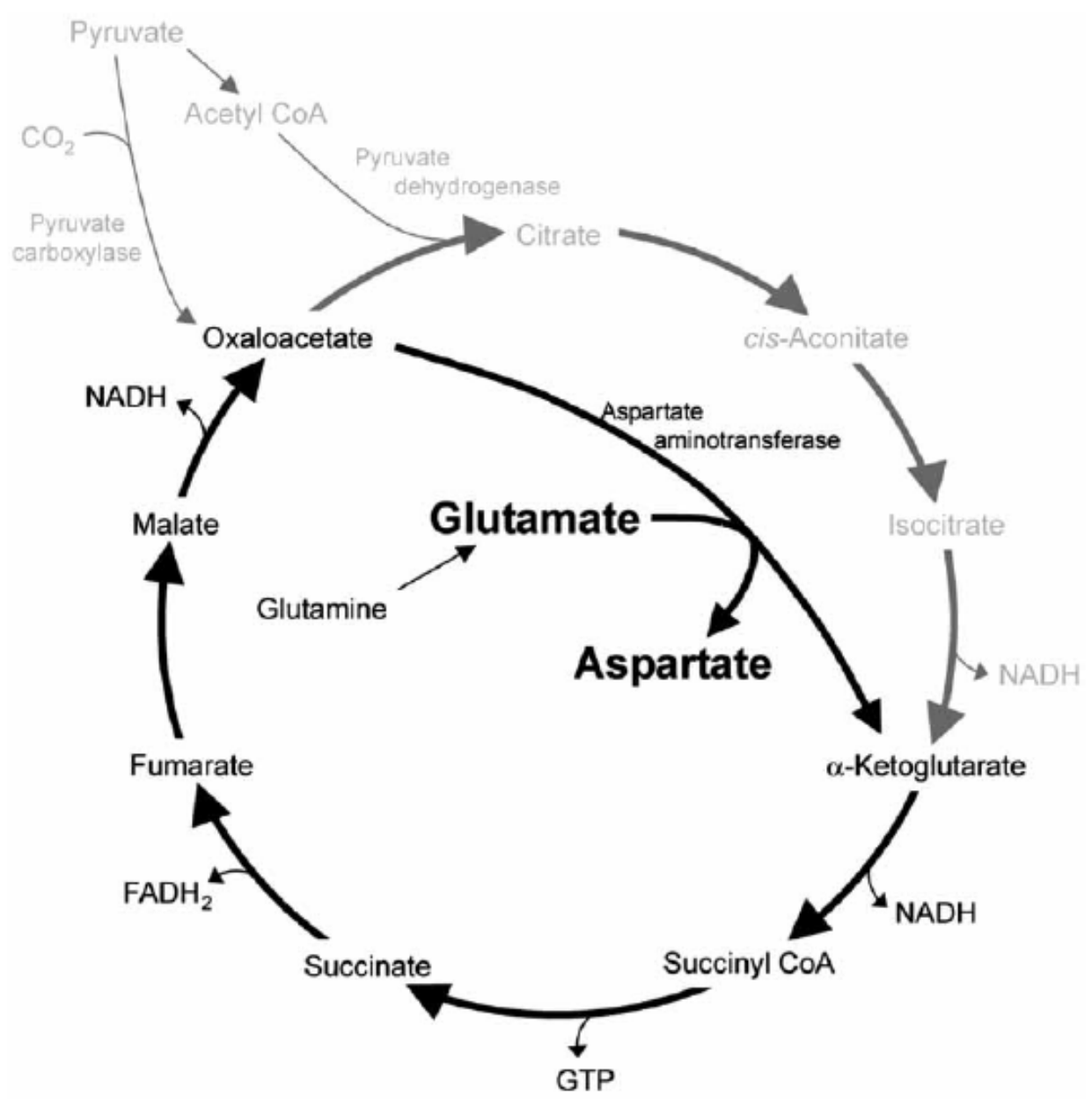

from Sutherland 2008

Fig. 2. Truncation of the Krebs Cycle during Hypoglycemia. Adapted from Sutherland: Medicinal Chemistry , 2008, 4; 379-85 


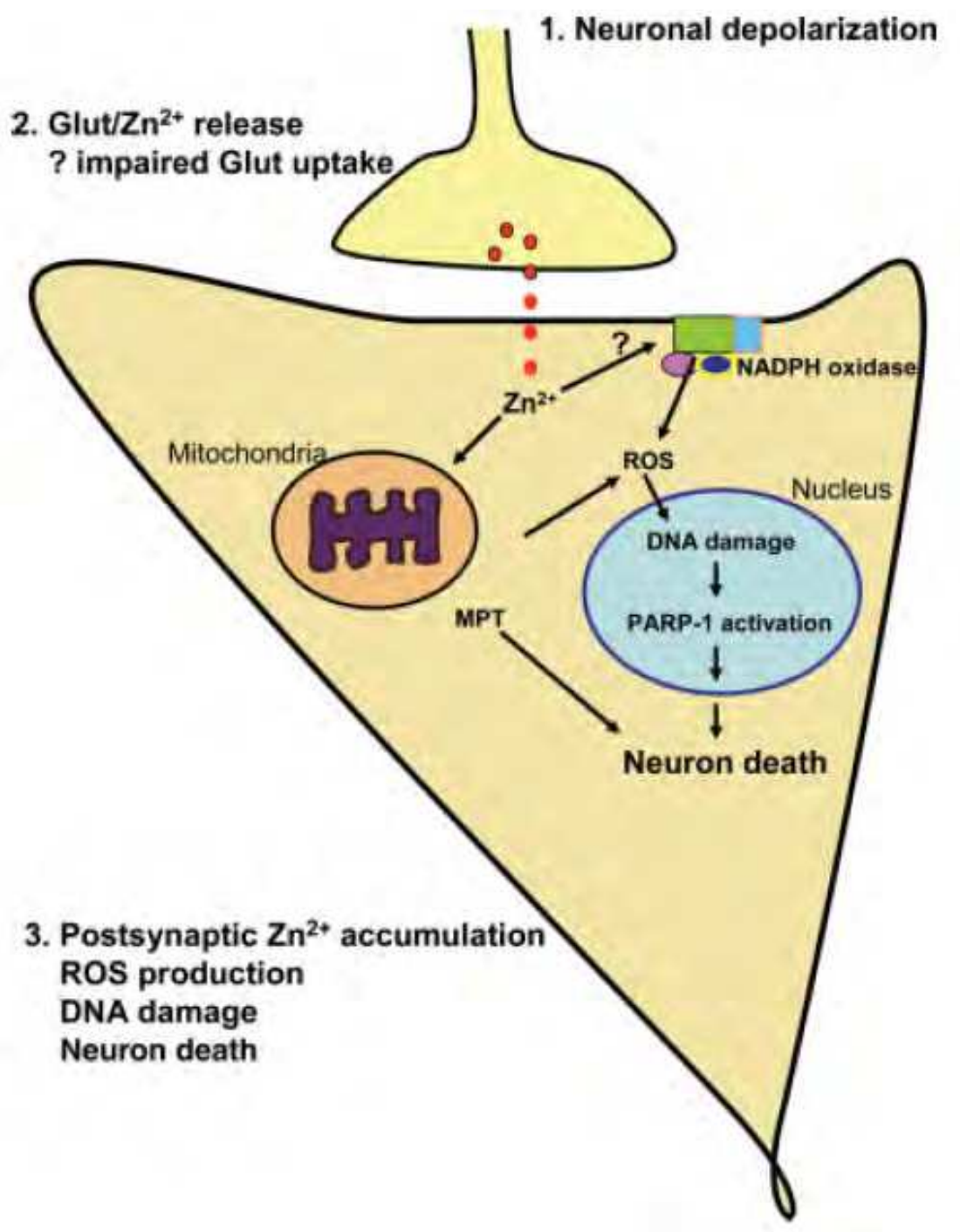

from Suh 2007

Key aspects of hypoglycemia-induced neuronal death. (1) Neuronal depolarization is induced by hypoglycemia. (2) Depolarization leads to release of glutamate, aspartate, and zinc. Impaired astrocyte uptake may contribute to increased glutamate extracellular levels. (3) Glutamate receptor activation and zinc influx induce production of reactive oxygen species (ROS) from mitochondria or NADPH oxidase, subsequent DNA damage and activation of poly(ADP-ribose) polymerase-1 (PARP-1), mitochondrial permeability transition (MPT), and cell death.

Fig. 3. Key Aspects of Hypoglycemia induced Neuronal Cell Death. From Suh : Glia55:12801286 (2007) 


\section{Clinical manifestations}

Neuronal function is known to worsen at lower levels of blood glucose. Under normal conditions, endogenous insulin secretion ceases at levels of around $4.5 \mathrm{mmol} / 1(81 \mathrm{mg} / \mathrm{dL})$. Counterregulatory hormones such as glucagon and epinephrine are later secreted in response to a fall in blood glucose to $3.8 \mathrm{mmol} / 1(68 \mathrm{mg} / \mathrm{dL})$. This causes autonomic symptoms such as sweating, irritability and tremulousness. At $2.8 \mathrm{mmol} / \mathrm{l}(50 \mathrm{mg} / \mathrm{dl})$ profound neurologlycopenic symptoms such as seizure, cognitive disturbance and confusion occur. Below this level coma appears, electroencephalogram (EEG) becomes flat, and neuron death occurs below $1 \mathrm{mmol} / \mathrm{L}(18 \mathrm{mmol} / \mathrm{dL})$ (see figure 4$){ }^{1}$

Hypoglycemia has been recognized as a clinical syndrome since 1924. ${ }^{28}$ In 1985, Malouf and Brust evaluated 125 patients with hypoglycemia presenting to a local hospital over a one year period. ${ }^{29} \mathrm{Among}$ their study cohort, sixty-five patients were obtunded, stuporous, or comatose. Another 38 had confusion or "bizarre" behavior, 10 were dizzy or tremulous, 9 had seizures, and 3 had hemiparesis. Diabetes mellitus, alcoholism, and sepsis, alone or in combination, accounted for $90 \%$ of predisposing conditions. Death occurred in $11 \%$, but was only attributed directly to hypoglycemia in one patient. Four patients had residual neurologic symptoms after resolution of hypoglycemia. ${ }^{29}$

The neurological manifestations of thirty patients with hypoglycemia from insulinoma were described by Daggett and Nabarro.30 They found that the most common presentation was confusion (20 cases), followed by coma (16 cases), seizures (8 cases) and weakness (8 cases). ${ }^{30}$ Their review included information about 220 other patients with hypoglycemia and insulinoma from 7 series. Among these, 152 cases had confusion, 82 had coma, 58 had seizures, 18 had headache, and 6 had weakness. ${ }^{30}$

Recurrent exposure to hypoglycemia, particularly in insulin treated type 1 diabetes, but to a lesser extent in type 2 diabetes can chronically impair the counterregulatory response to hypoglycemia. Two recognized syndromes are hypoglycemia associated autonomic failure (HAAF), and impaired awareness of hypoglycemia (IAH). After 20 years, around half of patients with type 1 diabetes have an impaired response of glucagon and epinephrine to hypoglycemia. ${ }^{31}$ Likely as a result of the blunted epinephrine response, IAH develops, as there are less of the typical clinical manifestations from epinephrine such as sweating and tremors. 32

Various other neurological manifestations of hypoglycemia have been described. These include headache, cognitive disturbance, hemiplegia, coma, and seizures.

\section{Headache}

Since 1933, fasting and hunger have been understood to precipitate migraine attacks.33-36 One of the largest studies to demonstrate fasting as a migraine precipitant included 1883 patients who responded to a questionnaire regarding dietary habits in the 24 hours before the migraine. Fasting was found to be a precipitating factor in $67 \%$ of patients. 37

A headache as a direct result of fasting, and without the autonomic features of migraine has been described. ${ }^{38}$ It is usually diffuse, nonpulsatile of moderate intensity, and should occur 16 hours after fasting, with resolution within 72 hours of food intake (see table 1). The lifetime prevalence of this type of headache is estimated to be $4.1 \% .39$

Various other headache types have been attributable to fasting for religious reasons, and come under various names such as Yom Kippur Headache and Ramadan Headache. A study 


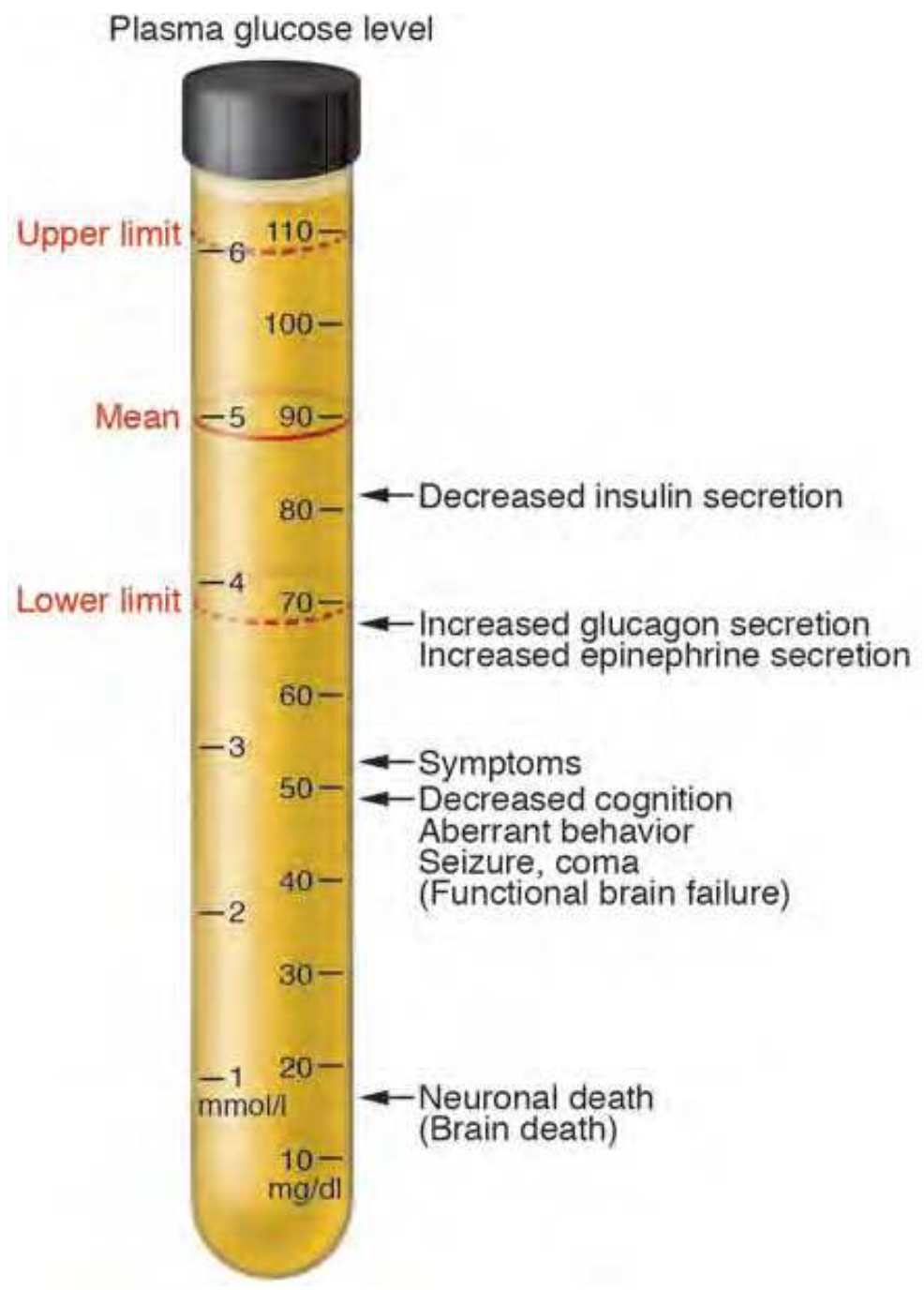

from Cryer, 2007

Fig. 4. Sequence of responses to falling arterial plasma glucose concentrations. The solid horizontal line indicates the mean and the dashed horizontal lines the upper and lower limits of physiological postabsorptive plasma glucoseconcentrations in humans. The glycemic thresholds for decrements in insulin secretion, increments in glucagon and epinephrine secretion, symptoms, and decrements in cognition. Have been defined in healthy humans (1) (see text). Those for seizure and coma and for neuronal death are extrapolated from clinical observations of humans (9) and studies in monkeys (12) as well as in other experimental animals (13-15). In this issue of the JCI, Suh and colleagues (13) report that glucose reperfusion increased brain neuronal death in their rodent model of profound hypoglycemia. 
Diagnostic criteria for headache attributed to fasting

(code 10.5)

A. Headache with at least one of the following characteristics and

fulfilling criteria $C$ and $D$ :

1. Frontal location

2. Diffuse pain

3. Non-pulsating quality

4. Mild or moderate intensity

B. The patient has fasted for $>16 \mathrm{~h}$

C. Headache develops during fasting

D. Headache resolves within $72 \mathrm{~h}$ after resumption of food intake

Table 1. International HA classification

comparing 211 patients who observed a total fast for 25 hours during Yom Kippur to 136 patients who did not found $82(39 \%)$ of the fasters complained of headache compared to $7 \%$ of non-fasters. ${ }^{40}$ Although abstinence from caffeine and nicotine was observed in the fasting group, this did not appear to have an influence on headache. A questionnaire given to 91 participants who had observed a complete fast on the first day of Ramadan and 25 who had not found $41 \%$ of the fasting group complained of headache, compared to only $8 \%$ in the control group $(\mathrm{p}=0.002) .{ }^{41}$ Although two of the subjects developed headache shortly after their last meal, suggesting to the author a possibility of reactive hypoglycemia, most of the headaches were attributable to caffeine withdrawal. Hypoglycemia was not formally evaluated in these studies.

Blau and Cumings attempted to identify a correlation between blood glucose and migraine. They had 12 migraine subjects fast for 19 hours, and measured blood sugar levels at regular intervals. Six of these subjects developed migraine, at an average of 11 to 14 hours after the beginning of the fast. The lowest blood sugar levels varied from 44 to $77 \mathrm{mg} / \mathrm{dl} .{ }^{42}$

Pearce recorded serial blood glucose levels in 20 migraine patients, and 10 matched controls after injecting 0.15 units $/ \mathrm{kg}$ body weight of insulin. Thirty minutes after the infusion, migraine patients had an average blood glucose level of $20.4 \mathrm{mg} / \mathrm{dl}$. After 2 hours of observation, only one (5\%) of the migraine patients developed a headache, and one $(5 \%)$ developed aura without headache. None of the control subjects developed headache, and most patients complained of mild faintness, sweating and palpitations. The author concluded that hypoglycemia may be implicated only in a minority of migraine patients, and that more complex metabolic factors are likely implicated. ${ }^{34}$

\section{Cognitive disturbance and dementia}

Hypoglycemia can affect cognitive performance and learning acutely. There are well documented reports and experimental trials linking various cognitive disturbances with hypoglycemia. A link between long term development of dementia and repeated hypoglycemia is more controversial.

Memory and learning was tested among thirty-six type 1diabetics during an episode of controlled hypoglycemia with a target blood glucose of $2.5 \mathrm{mmol} / 1$ for 60 minutes. Subjects attempted to memorize instructions during euglycemia and recall was assessed during hypoglycemia. Word recall, story recall, visual recall was also assessed during 
hypoglycemia. Euglycemia was then restored and delayed memory for the conventional tasks was tested. Euglycaemic control subjects performed the same tasks at blood glucose of $4.5 \mathrm{mmol} / \mathrm{l}$. Hypoglycemia impaired performance on the prospective memory task $(p=0.004)$ as well as both immediate and delayed recall for the word $(p<0.01)$ and story recall tasks $(p<0.01)$. No difference was found among subject with normal or impaired glycemic awareness. There was no significant change on the visual memory task. 43

McCrimmon et. Al. found diminished visual processing speed despite normal visual acuity in 20 non-diabetic subjects during controlled hypoglycemia. ${ }^{44}$ Significant reductions in speed of naming and labeling skills at hypoglycemia without associated impairment in accuracy has been observed. ${ }^{45}$ Immediate and delayed memory were impaired in 16 type 1 diabetic patients during controlled hypoglycemia of $2.5 \mathrm{mmol} / \mathrm{l}$ as assessed by the Trail Making B Test, and the Digit Symbol Test. ${ }^{46}$ Similar tests have shown impairment in visuospatial ability during hypoglycemia. 47

Tests of sensory perceptual processing, simple motor abilities, attention, learning, memory, language, and spatial and constructional abilities at plasma glucose levels of $2.2 \mathrm{mmol} / 1$ were diminished when compared to basal levels of performance at $8.9 \mathrm{mmol} / \mathrm{L}$ among 42 type 1 diabetics. Tests involving associative learning, attention, and mental flexibility were the most affected. ${ }^{48}$ Others have shown similar disruptions in various cognitive domains during hypoglycemia, leading to little doubt of the acute effects of hypoglycemia on cognition. 49

The role of hypoglycemic episodes on long term cognitive outcomes, and development of dementia is however more controversial. The 2007 Diabetes Control and Complications Trial (DCCT) and its follow-up Epidemiology of Diabetes Interventions and Complications (EDIC) followed 1144 diabetic patients for an average of 18 years. ${ }^{50}$ Forty percent of these patients reported at least one episode of hypoglycemic seizure or coma. Despite this, there was no associated decline in any cognitive domain. Those with elevated glycated hemoglobin had moderate declines in motor speed $(\mathrm{P}=0.001)$ and psychomotor efficiency $(\mathrm{P}<0.001) .50$

More recently, a longitudinal cohort of 16,667 patients showed a greater risk of dementia among those with hypoglycemic episodes, with an attributable risk of dementia of $2.39 \%$ per year (95\% CI $1.72 \%-3.01 \%) .51$ This study was limited in that it was a retrospective review of electronic medical records. Furthermore, reverse causation may account for the association. Patients with dementia may have been more likely to have irregular food intake and make dosing errors in their glycemic medications. Further trials are needed to investigate a possible association between hypoglycemia and long term cognition.

\section{Hypoglycemic hemiplegia}

The clinical syndrome of hypoglycemic hemiplegia has been recognized for over 50 years.52, 53 It appears to be rare, with case series reporting an incidence of $2 \%$ among those admitted with hypoglycemia. ${ }^{29}$ Objective weakness was found in 7 patients with hypoglycemia from insulinoma; 3 had hemiparesis, 2 had paraparesis and 2 had monoparesis. On average the weakness resolved over a period of $1 \mathrm{hr}$ to 3 days once normoglycaemia was maintained.29, 30 Wallis et. al. reviewed 16 patients presenting with weakness and blood glucose of less than $45 \mathrm{mg} / \mathrm{dl} .{ }^{54}$ Most patients were initially misdiagnosed as stroke, all but one were conscious during the attack, four had associated aphasia, most (12/16) had right sided weakness and all had resolution without recurrence within 15 minutes of glucose infusion. One of the 
patients had a total of four episodes of transient hemiplegia before hypoglycemia was diagnosed. He was left with permanent dysarthria and ataxia. One patient died after multiple recurrent hypoglycemic episodes and subsequent deep coma related to insulinoma. Autopsy of this patient showed diffuse cortical injury, but no focal lesions. ${ }^{54}$

Another review involving 29 patients found $72 \%$ were caused by insulin treatment, and mean serum glucose was $35 \mathrm{mg} / \mathrm{dL}$. Most (78\%) had recurrent attacks, and on average 3.5 attacks occurred before a diagnosis of hypoglycemic hemiparesis was made. Interestingly, the majority of patients $(72 \%)$ had right sided weakness, most with aphasia. ${ }^{55}$

Hypoglycemia must be excluded in a patient presenting with symptoms consistent with transient ischemic attack or stroke. Current guidelines for the treatment of stroke patients with IV tissue plasminogen activator exclude those with a glucose level below $50 \mathrm{mg} / \mathrm{dL}$ if their symptoms are likely attributable to the hypoglycemia. ${ }^{56}$ This presentation is however much more rare than ischemic stroke. During a one year period, three patients were admitted with hypoglycemic hemiplegia compared to 400 with ischemic stroke in an urban hospital. ${ }^{29}$

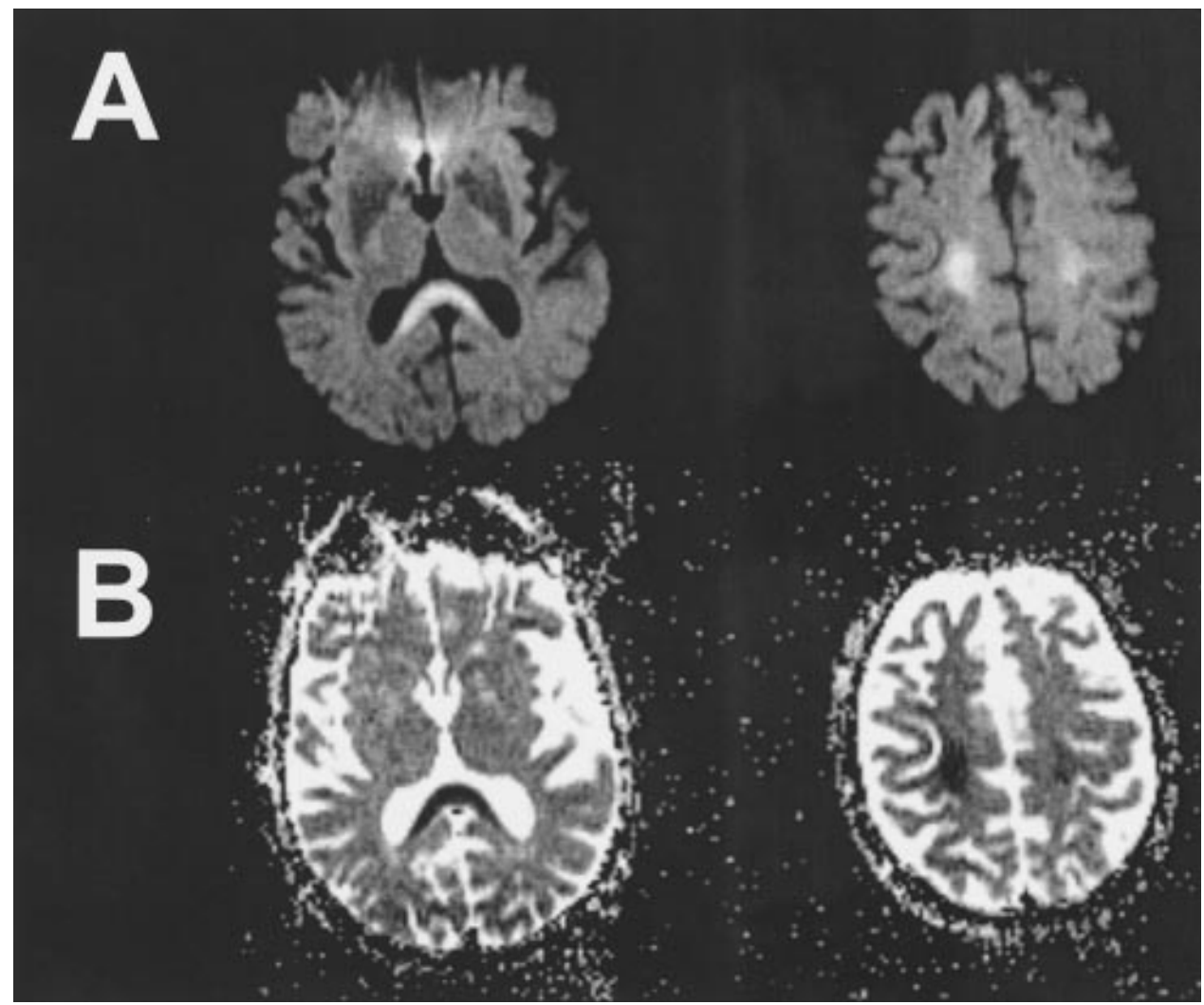

From Botcher 2005

Fig. 5. A, Initial DWI (repetition time/echo time/_4100/96/90;_1000 s/mm2; field of view $230 \mathrm{~mm}$; matrix: 128_128) with increased signal intensities in bilateral corona radiata and splenium. B, Initial ADC maps with signal reduction also in bilateral corona radiata and splenium corresponding to DWI images. 
Reports suggest that brain imaging during hypoglycemic hemiplegia, and coma may be similar to that observed during ischemic stroke. Specifically, in the setting of ischemic stroke, MRI shows restricted diffusion of water molecules due to ionic pump failure. This leads to restriction on diffusion weighted imaging (DWI) and prolongation of apparent diffusion coefficient (ADC). ADC changes were found to occur in association with the onset of EEG isoelectricity in insulin induced hypoglycemic rats. ${ }^{57}$

Case reports have shown ADC and DWI changes in patients with hypoglycemic hemiplegia. These changes usually reverse after clinical improvement with glucose recussitation.58-60 Unlike ischemic stroke, hypoglycemic changes on MRI are often bilateral, affect the cortex, hippocampus and basal ganglia, and do not necessarily correspond to a vascular territory(see figure 5). ${ }^{61}$

Although hypoglycemic hemiplegia is initially clinically indistinguishable from an ischemic stroke, the pathophysiology is likely different. Autopsy studies have not demonstrated lesions in vascular territories, but rather diffuse damage.11, 54 Hypoglycemia has been shown to produce vasodilatation in animals, unlike vasoconstriction seen in stroke.62 Although case reports have shown patients with hypoglycemic hemiplegia and associated carotid artery stenosis, most others have not validated this observation. ${ }^{54,55,63}$ The notion of underlying cerebrovascular disease as a cause for hypoglycemic hemiplegia does not seem to be supported.

Profound hypoglycemia causes tissue alkalosis resulting from ammonia formation and consumption of metabolic acids, unlike tissue acidosis seen in cerebral ischemia. 64 Hypoglycemic brain death preferentially affects neurons, whereas ischemia tends to affect glial and endothelial cells as well. ${ }^{65}$ Hypoglycemia generally spares axons while damage from ischemia affects all parts of the neuron. ${ }^{66}$

\section{Hypoglycemic coma}

One of the most feared, and occasionally devastating effects of hypoglycemia is coma. The relationship between insulin treatment and coma was first recognized by Sakel in the 1930s. ${ }^{67} \mathrm{He}$ and others noticed that when treating schizophrenics with insulin (a now abandoned practice), a duration of treatment under 30 minutes allowed the patients to recover from the coma, but much longer, the coma would be irreversible.67, 68 Insulin induced hypoglycemia to a level of $0.7 \mathrm{mmol} / 1(13 \mathrm{mg} / \mathrm{dl})$ was found to produce significant brain damage after 5-6 hours in monkeys. 69

A retrospective analysis over a 7 year period evaluated 102 patients admitted with coma and blood glucose of below $49 \mathrm{mg} / \mathrm{dL}$, and improvement with glucose administration. Most patients were type 2 diabetics (92/102) taking glycemic agents. Risk factors included age over 60, renal dysfunction decreased energy intake or infection. Sixty two patients responded within 12 hours of treatment, while the others had no resolution for up to 72 hours. Death occur in 5 patients(4.9\%)..$^{70}$

A prospective one year study found sixty five of 125 (52\%) admissions for hypoglycemia presented with obtundation, stupor or coma. ${ }^{29}$ While the length of time in coma could not always be determined, the one death related to hypoglycemia occurred in a patient with coma lasting over 20 hours. Of the 11 patients determined to be comatose for 12 hours or more, 10 remained comatose. Blood glucose level did not predict coma, as there was a wide range of blood glucose levels among these comatose patients, and similar results in those without coma. ${ }^{29}$ 
MR images of those in persistent vegetative state from hypoglycemia revealed lesions in the bilateral basal ganglia, cerebral cortex, substantia nigra, and hippocampus, which suggests the particular vulnerability of these areas. ${ }^{61}$ Involvement of the basal ganglia seems to portend a worse outcome, though evidence is limited to case reports. ${ }^{71}$

Two markers of neuronal injury, NSE and S-100 may predict death or otherwise poor outcome in profound hypoglycemic coma. They showed no change in diabetics with mild hypoglycemic episodes, but were markedly elevated in 3 patients who died from hypoglycemic brain injury. ${ }^{72,} 73$ The disappearance of EEG activity is a prerequisite for hypoglycemia induced brain damage. ${ }^{66}$

\section{Seizures}

In autopsy studies, the cortex and hippocampus were most frequently involved in hypoglycemic brain damage. ${ }^{11}$ These areas are also commonly involved in seizures from other causes.

In a prospective study of symptomatic hypoglycemia admissions over one year, 9 of 125 $(7.2 \%)$ patients presented with seizures related to hypoglycemia. Among the 9 seizure patients, 3 had comorbid epilepsy, and 6 were intoxicated with alcohol. The majority of the seizures were generalized tonic clonic, most recurred, and one patient had status epilepticus. ${ }^{29}$

The landmark Diabetes Control and Complications Trial found 16 episodes of coma or seizure per 100 patient-years in the aggressive glucose control group, compared to 5 in the moderate control group. ${ }^{74}$ Another prospective study had a rate of severe events (the combination of seizure or coma) at 4.8/100 patient-years. Most of the severe events were seizures, and risk factors were age under 6 and glycosalated hemoglobin $<7 \% .75$

A prospective study of 1382 patients with new onset seizures found that hypoglycemia was never found to be the inciting cause. ${ }^{76}$ This apparent discrepancy may be due to the fact that serum glucose was drawn after dextrose was given to presenting patients. Furthermore, this study focused on all those presenting with seizures, indicating hypoglycemia leading to seizures may be a rare event in non-diabetics.

The NLSTEPSS study evaluated causes of status epilepticus in children, and found $4 \%$ were from metabolic causes. ${ }^{77}$ Metabolic causes of status epilepticus were found in $11 \%$ of adult patients. ${ }^{78}$ Unfortunately, these studies did not separate blood glucose from other metabolic causes. ${ }^{78}$

Quantitative EEG recordings have shown that epileptiform activity (spikes) occurred at higher blood glucose levels in diabetic than non-diabetic children, and overall, occurred at higher glucose levels in children $(3 \mathrm{mmol} / \mathrm{l})$ compared with adults $(2 \mathrm{mmol} / \mathrm{l})$ (see figure 6$) .79$,

80 In a case review of four children wearing a continuous glucose monitor, hypoglycemia occurred on average 2-4 hours before seizure onset. ${ }^{73}$

During hypoglycemia, multiple metabolic derangements occur. In particular, the excitatory amino acids glutamate and aspartate increase out of proportion to a slight rise in extracellurlar GABA. The resulting brain excitatory milieu may account for seizure activity. 64

Investigators showed that fasting and insulin infusion in rats increased the incidence of barrel rotations, which is a characteristic phenotype of hypoglycemic seizures in the animal. In particular, they showed a decreased release of GABA in the substantia nigra pars reticulate in rats with seizures. ${ }^{81}$ 


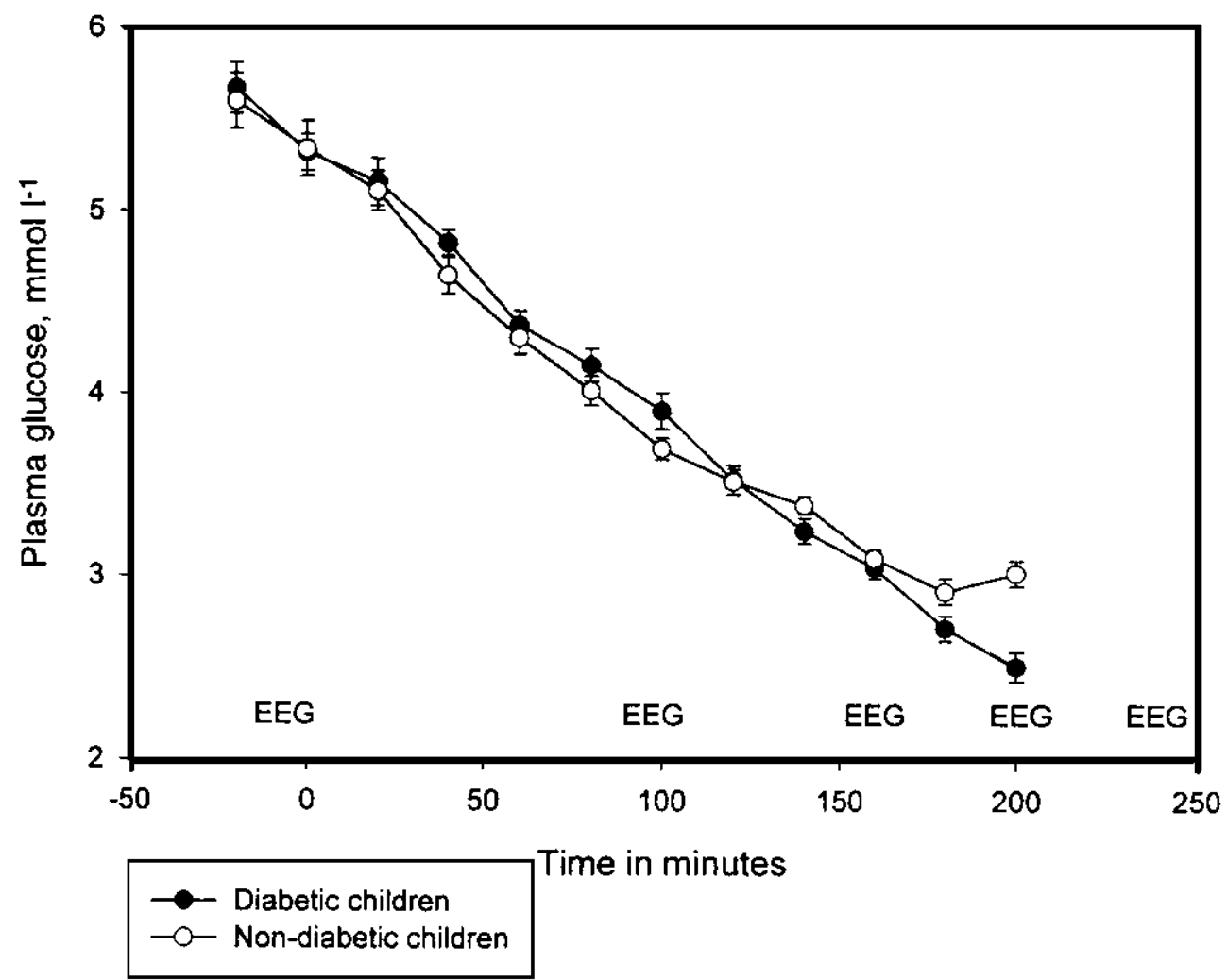

Fig. 6. Plasma glucose levels (mean \pm SEM) during the hypoglycemic clamp, and approximate time at EEG regis- trations, in the 19 diabetic (solid circles) and 17 non-diabetic children (open circles) Bjorgaas 1998

\section{Conclusion}

Hypoglycemia has profound effects on the brain. At the cellular level, energy failure and excitotoxicity lead to interruptions of many critical cellular activities. Clinically, this can manifest as headache, seizure, stroke-like episodes, cognitive dysfunction, and coma.

\section{References}

[1] Cryer PE. Hypoglycemia, functional brain failure, and brain death. The Journal of Clinical Investigation. 2007;117:868

[2] Magistretti PJ, Pellerin L. Cellular mechanisms of brain energy metabolism. Relevance to functional brain imaging and to neurodegenerative disorders. Ann N Y Acad Sci. 1996;777:380-387

[3] Pellerin L. Food for thought: The importance of glucose and other energy substrates for sustaining brain function under varying levels of activity. Diabetes $\mathcal{E}$ Metabolism.36:S59 
[4] Cooper JR BF, Roth RH. The biochemical basis of neuropharmacology. New York: Oxford University Press; 1974.

[5] Pellerin L, Magistretti PJ. Glutamate uptake into astrocytes stimulates aerobic glycolysis: A mechanism coupling neuronal activity to glucose utilization. Proc Natl Acad Sci U S A. 1994;91:10625-10629

[6] Vannucci SJ, Simpson IA. Synopsis of the workshop entitled "is lactate a nutrient for neurons" held at the brain energy meeting in trondheim, norway. Journal of Neuroscience Research. 2001;66:821

[7] Brown AM. Brain glycogen re-awakened. Journal of Neurochemistry. 2004;89:537

[8] Brown A. M. WRE, Baltan Tekkök S., and Ransom B. R. Functional insulin receptors are selectively expressed on cns astrocytes. Soc Neurosci Abstr. 2002;28:581

[9] Robinson AM, Williamson DH. Physiological roles of ketone bodies as substrates and signals in mammalian tissues. Physiol Rev. 1980;60:143-187

[10] Auer RN, Wieloch T, Olsson Y, Siesjö BK. The distribution of hypoglycemic brain damage. Acta Neuropathologica. 1984;64:177

[11] Auer RN, Hugh J, Cosgrove E, Curry B. Neuropathologic findings in three cases of profound hypoglycemia. Clin Neuropathol. 1989;8:63-68

[12] Sandberg M, Butcher SP, Hagberg H. Extracellular overflow of neuroactive amino acids during severe insulin-induced hypoglycemia: In vivo dialysis of the rat hippocampus. J Neurochem. 1986;47:178-184

[13] Engelsen B, Westerberg E, Fonnum F, Wieloch T. Effect of insulin-induced hypoglycemia on the concentrations of glutamate and related amino acids and energy metabolites in the intact and decorticated rat neostriatum. J Neurochem. 1986;47:1634-1641

[14] Suh SW, Hamby AM, Swanson RA. Hypoglycemia, brain energetics, and hypoglycemic neuronal death. Glia. 2007;55:1280-1286

[15] Sutherland GR, Tyson RL, Auer RN. Truncation of the krebs cycle during hypoglycemic coma. Med Chem. 2008;4:379-385

[16] Olney JW, Sharpe LG. Brain lesions in an infant rhesus monkey treated with monsodium glutamate. Science. 1969;166:386-388

[17] Wieloch T, Engelsen B, Westerberg E, Auer R. Lesions of the glutamatergic corticostriatal projections in the rat ameliorate hypoglycemic brain damage in the striatum. Neurosci Lett. 1985;58:25-30

[18] Wieloch T. Hypoglycemia-induced neuronal damage prevented by an n-methyl-daspartate antagonist. Science. 1985;230:681-683

[19] Sandberg M, Nystrom B, Hamberger A. Metabolically derived aspartate--elevated extracellular levels in vivo in lodoacetate poisoning. J Neurosci Res. 1985;13:489-495

[20] Olney JW. Inciting excitotoxic cytocide among central neurons. Adv Exp Med Biol. 1986;203:631-645

[21] Choi DW. Ionic dependence of glutamate neurotoxicity. J Neurosci. 1987;7:369-379

[22] Choi DW. Glutamate neurotoxicity and diseases of the nervous system. Neuron. 1988;1:623-634

[23] Choi DW, Maulucci-Gedde M, Kriegstein AR. Glutamate neurotoxicity in cortical cell culture. J Neurosci. 1987;7:357-368

[24] MacDermott AB, Mayer ML, Westbrook GL, Smith SJ, Barker JL. Nmda-receptor activation increases cytoplasmic calcium concentration in cultured spinal cord neurones. Nature. 1986;321:519 
[25] Dugan LL, Sensi SL, Canzoniero LM, Handran SD, Rothman SM, Lin TS, Goldberg $\mathrm{MP}$, Choi DW. Mitochondrial production of reactive oxygen species in cortical neurons following exposure to n-methyl-d-aspartate. J Neurosci. 1995;15:6377-6388

[26] Yu SW, Wang H, Poitras MF, Coombs C, Bowers WJ, Federoff HJ, Poirier GG, Dawson TM, Dawson VL. Mediation of poly(adp-ribose) polymerase-1-dependent cell death by apoptosis-inducing factor. Science. 2002;297:259-263

[27] Ha HC, Snyder SH. Poly(adp-ribose) polymerase is a mediator of necrotic cell death by atp depletion. Proc Natl Acad Sci U S A. 1999;96:13978-13982

[28] Harris S. Hyperinsulinism and dysinsulinism. Journal of the American Medical Association. 1924;83:729-733

[29] Malouf R, Brust JCM. Hypoglycemia: Causes, neurological manifestations, and outcome. Annals of Neurology. 1985;17:421

[30] Daggett P, Nabarro J. Neurological aspects of insulinomas. Postgraduate Medical Journal. 1984;60:577-581

[31] Gerich JE BG. Counterregulatory failure. In: Frier BM FB, ed. Hypoglycaemia and diabetes: Clinical and physiological aspects. London: Edward Arnold; 1993:253-267.

[32] BM F. Impaired awareness of hypoglycaemia. In: Frier BM FM, ed. Hypoglycaemia in clinical diabetes. Chichester: John Wiley \& Sons; 2007:141-170.

[33] Critchley M, Ferguson F. Migraine. The Lancet. 1933;221:123

[34] Pearce J. Insulin induced hypoglycaemia in migraine. Journal of Neurology, Neurosurgery E Psychiatry. 1971;34:154-156

[35] Jacome DE. Hypoglycemia rebound migraine. Headache: The Journal of Head and Face Pain. 2001;41:895

[36] Gray PA BH. Hypoglycemic headache. Endocrinology. 1935;19:549-560

[37] Dalton K. Food intake prior to a migraine attack--study of 2,313 spontaneous attacks. Headache. 1975;15:188-193

[38] The international classification of headache disorders: 2nd edition. Cephalalgia. 2004;24 Suppl 1:9-160

[39] Rasmussen BK, Olesen J. Symptomatic and nonsymptomatic headaches in a general population. Neurology. 1992;42:1225-1231

[40] Mosek A, Korczyn AD. Yom kippur headache. Neurology. 1995;45:1953-1955

[41] Awada A, al Jumah M. The first-of-ramadan headache. Headache. 1999;39:490-493

[42] Blau JN, Cumings JN. Method of precipitating and preventing some migraine attacks. Br Med J. 1966;2:1242-1243

[43] Warren R, Zammitt N, Deary I, Frier B. The effects of acute hypoglycaemia on memory acquisition and recall and prospective memory in type 1 diabetes. Diabetologia. 2007;50:178

[44] McCrimmon RJ, Deary IJ, Huntly BJP, MacLeod KJ, Frier BM. Visual information processing during controlled hypoglycaemia in humans. Brain. 1996;119:1277-1287

[45] Holmes CS, Koepke KM, Thompson RG, Gyves PW, Weydert JA. Verbal fluency and naming performance in type i diabetes at different blood glucose concentrations. Diabetes Care. 1984;7:454-459

[46] Sommerfield AJ, Deary IJ, McAulay V, Frier BM. Short-term, delayed, and working memory are impaired during hypoglycemia in individuals with type 1 diabetes. Diabetes Care. 2003;26:390-396

[47] Wright RJ, Frier BM, Deary IJ. Effects of acute insulin-induced hypoglycemia on spatial abilities in adults with type 1 diabetes. Diabetes Care. 2009;32:1503-1506 
[48] Draelos MT, Jacobson AM, Weinger K, Widom B, Ryan CM, Finkelstein DM, Simonson DC. Cognitive function in patients with insulin-dependent diabetes mellitus during hyperglycemia and hypoglycemia. The American Journal of Medicine. 1995;98:135

[49] Widom B, Simonson DC. Glycemic control and neuropsychologic function during hypoglycemia in patients with insulin-dependent diabetes mellitus. Ann Intern Med. 1990;112:904-912

[50] Long-term effect of diabetes and its treatment on cognitive function. New England Journal of Medicine. 2007;356:1842-1852

[51] Whitmer RA, Karter AJ, Yaffe K, Quesenberry CP, Selby JV. Hypoglycemic episodes and risk of dementia in older patients with type 2 diabetes mellitus. JAMA: The Journal of the American Medical Association. 2009;301:1565-1572

[52] Wortis J BK, Orenstein L, Rosenbaum I. Further experiences at bellevue hospital with the hypoglycemic insulin treatment of schizophrenia. American Journal of Psychiatry. 1937;94:153-158

[53] JohnWortis KB, Larry Orenstein, Innis Rosenbaum. Further experiences at bellevue hospital with the hypoglycemic insulin treatment of schizophrenia. American Journal of Psychiatry. 1937;94:153-158

[54] Wallis WE, Donaldson I, Scott RS, Wilson J. Hypoglycemia masquerading as cerebrovascular disease (hypoglycemic hemiplegia). Ann Neurol. 1985;18:510-512

[55] Foster JW, Hart RG. Hypoglycemic hemiplegia: Two cases and a clinical review. Stroke. 1987;18:944-946

[56] Adams HP, Jr., del Zoppo G, Alberts MJ, Bhatt DL, Brass L, Furlan A, Grubb RL, Higashida RT, Jauch EC, Kidwell C, Lyden PD, Morgenstern LB, Qureshi AI, Rosenwasser RH, Scott PA, Wijdicks EF. Guidelines for the early management of adults with ischemic stroke: A guideline from the american heart association/american stroke association stroke council, clinical cardiology council, cardiovascular radiology and intervention council, and the atherosclerotic peripheral vascular disease and quality of care outcomes in research interdisciplinary working groups: The american academy of neurology affirms the value of this guideline as an educational tool for neurologists. Circulation. 2007;115:e478-534

[57] Hasegawa Y, Formato JE, Latour LL, Gutierrez JA, Liu K-F, Garcia JH, Sotak CH, Fisher M, Brayden JE. Severe transient hypoglycemia causes reversible change in the apparent diffusion coefficient of water. Stroke. 1996;27:1648-1656

[58] Bottcher J, Kunze A, Kurrat C, Schmidt P, Hagemann G, Witte OW, Kaiser WA. Localized reversible reduction of apparent diffusion coefficient in transient hypoglycemia-induced hemiparesis. Stroke. 2005;36:e20-22

[59] Cordonnier C, Oppenheim C, Lamy C, Meder JF, Mas JL. Serial diffusion and perfusion-weighted $\mathrm{mr}$ in transient hypoglycemia. Neurology. 2005;65:175

[60] Hasegawa Y, Formato JE, Latour LL, Gutierrez JA, Liu KF, Garcia JH, Sotak CH, Fisher M. Severe transient hypoglycemia causes reversible change in the apparent diffusion coefficient of water. Stroke. 1996;27:1648-1655; discussion 1655-1646

[61] Fujioka M, Okuchi K, Hiramatsu K-I, Sakaki T, Sakaguchi S, Ishii Y. Specific changes in human brain after hypoglycemic injury. Stroke. 1997;28:584-587

[62] Dieguez G, Fernandez N, Garcia JL, Garcia-Villalon AL, Monge L, Gomez B. Role of nitric oxide in the effects of hypoglycemia on the cerebral circulation in awake goats. Eur J Pharmacol. 1997;330:185-193 
[63] Portnoy HD. Transient "ischemic" attacks produced by carotid stenosis and hypoglycemia. Neurology. 1965;15:830-832

[64] Auer RN. Progress review: Hypoglycemic brain damage. Stroke. 1986;17:699-708

[65] Helgason CM. Blood glucose and stroke. Stroke. 1988;19:1049-1053

[66] Auer RN. Hypoglycemic brain damage. Forensic Science International. 2004;146:105

[67] Sakel M. The methodical use of hypoglycemia in the treatment of psychoses. American Journal of Psychiatry. 1937;94:111-129

[68] Fazekas JF, Alman, R.W., Parrish A.E. Irreversible posthypoglycemic coma. American Journal of Medical Science. 1951;222:640-643

[69] Kahn KJ, Myers, R.E. Insulin-inducedhypoglycaemia in the non-human primate: Clinical consequences. Brain hypoxia. 1971:185-194

[70] Ben-Ami H, Nagachandran P, Mendelson A, Edoute Y. Drug-induced hypoglycemic coma in 102 diabetic patients. Arch Intern Med. 1999;159:281-284

[71] Finelli PF. Diffusion-weighted mr in hypoglycemic coma. Neurology. 2001;57:933

[72] Strachan MWJ, Abraha HD, Sherwood RA, Lammie GA, Deary IJ, Ewing FME, Perros $\mathrm{P}$, Frier BM. Evaluation of serum markers of neuronal damage following severe hypoglycaemia in adults with insulin-treated diabetes mellitus. Diabetes/Metabolism Research and Reviews. 1999;15:5

[73] Buckingham B, Wilson DM, Lecher T, Hanas R, Kaiserman K, Cameron F. Duration of nocturnal hypoglycemia before seizures. Diabetes Care. 2008;31:2110-2112

[74] The effect of intensive treatment of diabetes on the development and progression of long-term complications in insulin-dependent diabetes mellitus. New England Journal of Medicine. 1993;329:977-986

[75] Davis EA, Keating B, Byrne GC, Russell M, Jones TW. Hypoglycemia: Incidence and clinical predictors in a large population-based sample of children and adolescents with iddm. Diabetes Care. 1997;20:22-25

[76] Singh RK, Stephens S, Berl MM, Chang T, Brown K, Vezina LG, Gaillard WD. Prospective study of new-onset seizures presenting as status epilepticus in childhood. Neurology.74:636-642

[77] Chin RFM, Neville BGR, Peckham C, Bedford H, Wade A, Scott RC. Incidence, cause, and short-term outcome of convulsive status epilepticus in childhood: Prospective population-based study. The Lancet. 2006;368:222

[78] Towne AR, Pellock JM, Ko D, DeLorenzo RJ. Determinants of mortality in status epilepticus. Epilepsia. 1994;35:27

[79] Bjorgaas M, Sand T, Vik T, Jorde R. Quantitative eeg during controlled hypoglycaemia in diabetic and non-diabetic children. Diabet Med. 1998;15:30-37

[80] Pramming S, Thorsteinsson B, Stigsby B, Binder C. Glycaemic threshold for changes in electroencephalograms during hypoglycaemia in patients with insulin dependent diabetes. Br Med J (Clin Res Ed). 1988;296:665-667

[81] Velíšková J, Chudomel O, Poon KL, Marshall B, Velíšek L. The involvement of the substantia nigra pars reticulata in hypoglycemic seizures. Epilepsia. 2007;48:106 


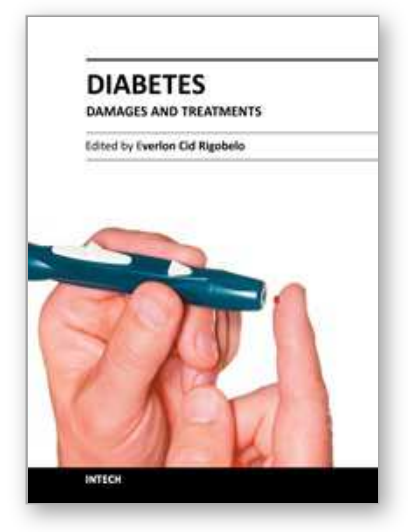

\author{
Diabetes - Damages and Treatments \\ Edited by Prof. Everlon Rigobelo
}

ISBN 978-953-307-652-2

Hard cover, 348 pages

Publisher InTech

Published online 09, November, 2011

Published in print edition November, 2011

Over the last few decades the prevalence of diabetes has dramatically grown in most regions of the world. In 2010, 285 million people were diagnosed with diabetes and it is estimated that the number will increase to 438 million in 2030. Hypoglycemia is a disorder where the glucose serum concentration is usually low. The organism usually keeps the serum glucose concentration in a range of 70 to $110 \mathrm{~mL} / \mathrm{dL}$ of blood. In hypoglycemia the glucose concentration normally remains lower than $50 \mathrm{~mL} / \mathrm{dL}$ of blood. Hopefully, this book will be of help to many scientists, doctors, pharmacists, chemicals, and other experts in a variety of disciplines, both academic and industrial. In addition to supporting researcher and development, this book should be suitable for teaching.

\title{
How to reference
}

In order to correctly reference this scholarly work, feel free to copy and paste the following:

William P. Neil and Thomas M. Hemmen (2011). Neurologic Manifestations of Hypoglycemia, Diabetes Damages and Treatments, Prof. Everlon Rigobelo (Ed.), ISBN: 978-953-307-652-2, InTech, Available from: http://www.intechopen.com/books/diabetes-damages-and-treatments/neurologic-manifestations-ofhypoglycemia

\section{INTECH}

open science | open minds

\section{InTech Europe}

University Campus STeP Ri Slavka Krautzeka 83/A 51000 Rijeka, Croatia Phone: +385 (51) 770447 Fax: +385 (51) 686166 www.intechopen.com

\section{InTech China}

Unit 405, Office Block, Hotel Equatorial Shanghai No.65, Yan An Road (West), Shanghai, 200040, China 中国上海市延安西路65号上海国际贵都大饭店办公楼405单元 Phone: +86-21-62489820

Fax: +86-21-62489821 
(C) 2011 The Author(s). Licensee IntechOpen. This is an open access article distributed under the terms of the Creative Commons Attribution 3.0 License, which permits unrestricted use, distribution, and reproduction in any medium, provided the original work is properly cited. 